\title{
Localização no futebol de robôs humanóides
}

\section{Gabriel Previato de Andrade*, Esther L. Colombini}

\section{Resumo}

Este trabalho tem por objetivo estimar a posição de um robô humanóide em um campo de futebol nos padrões da Robocup, utilizando um extrator de características para obter a distância do robô aos objetos e às linhas no campo e usar essas distâncias como input para um filtro de partículas Monte Carlo.

\section{Palavras-chave:}

Localização, visão, odometria

\section{Introdução}

Atualmente são encontradas na literatura diversas abordagens para a localização de um robô em um campo de futebol, como aquele das tarefas da RoboCup. $\mathrm{Na}$ categoria de robôs humanoides, na qual este trabalho foca, os robôs são construídos para que tenham estrutura semelhante à humana, portanto são equipados apenas com câmeras direcionais e unidades inerciais (IMU). Neste sentido, técnicas de localização para estimar a pose do robô utilizando câmeras direcionais e o modelo de movimentação do robô devem ser empregadas.

\section{Resultados e Discussão}

Para a simulação do ambiente físico e do robô, foi utilizado o software de simulação V-REP ${ }^{[1]}$, desenvolvido pela empresa Coppelia Robotics. O V-REP além de fornecer um ambiente de simulação com propriedades físicas próximas à realidade também oferece uma versão pronta do robô NAO, o qual utilizamos no projeto. Assim, montou-se um campo de futebol com as especificações da categoria ${ }^{[2]}$ conforme mostrado na Figura 1 ..

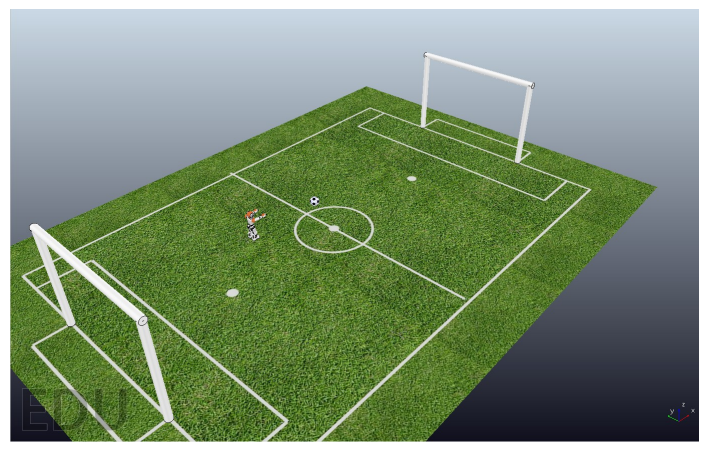

Figura 1. Campo de futebol no ambiente de simulação do V-REP

Através de um extrator de características, baseado em segmentação de cores utilizando técnicas propostas por Georkais $^{[3]}$ e Magalhães ${ }^{[4]}$, obtemos os landmarks do campo: as traves dos gols e cantos do campo. E com os landmarks segmentados, através das características da câmera e do campo visual horizontal e vertical da câmera, conseguimos calcular a distância do gol até os landmarks.

Um filtro de partículas de localização Monte Carlo (MCL) foi utilizado para estimar a pose do robô, baseado na distância do robô aos landmarks obtidos pelo extrator de características e também do modelo cinemático do robô. Utilizamos para validação do modelo proposto, um cenário em que o robô partia correndo de uma extremidade do campo à outra, calculando o erro do resultado final da posição estimada pelo filtro de partícula e a posição real do robô. Esse cenário mostrou que o extrator de características não era bom, pois com o robô em velocidade, muitas extrações continham falsos positivos e medições de distância incorreta, o que refletiu no MCL.

Aumentando o número de partículas, conseguimos fazer com que o erro médio nos eixos $X$ e $Y$ fossem menores, ainda que não sejam completamente satisfatórias, como mostra a Tabela 1.

Tabela 1. Erro médio nos eixos $X$ e $Y$ obtidos pelo Filtro de Partículas com 100 e 1000 partículas.

\begin{tabular}{|c|c|c|}
\hline $\begin{array}{c}\text { Número de } \\
\text { partículas }\end{array}$ & Erro médio X $(\mathrm{m})$ & Erro médio $\mathrm{Y}(\mathrm{m})$ \\
\hline 100 & 0.7884 & 0.9471 \\
\hline 1000 & 0.4622 & 0.6587 \\
\hline
\end{tabular}

\section{Conclusão}

As falhas apresentadas pelo extrator de características geram um gargalo grande na estimativa da posição do robô em uma situação em que este está se locomovendo rapidamente. Vimos que é necessário utilizar um extrator que forneça resultados mais confiáveis e assertivos.

Para trabalhos futuros, a utilização de um extrator baseado em técnicas de Deep Learning como a proposta por Mancini ${ }^{[5]}$ podem fornecer dados mais confiáveis ao filtro de partículas, de maneira que a estimativa final de posição seja mais correta.

\section{Agradecimentos}

Agradeço ao CNPq pelo fomento através da bolsa de iniciação científica do PIBIC na quota 2017/2018 e agradeço a Profa. Dra. Esther Colombini, orientadora deste trabalho.

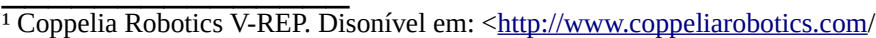
$>$. Acessado em 01/07/2018.

${ }^{2}$ RoboCup - "RoboCup Soccer Humanoid League Laws of the Game* 5 2016/2017”. Disponível em:

<http://www.robocuphumanoid.org/wp-content/uploads/RCHL-2017-final-

2.pdf $>$. Acessado em 10/07/2018.

${ }^{3}$ Georgakis G., Field Landmark Recognition and Localization for the Robotstadium Online Soccer Competition, 2012, 112f, Technical Univesity of Crete, Greece.

${ }^{4}$ Magalhães, G. B., Colombini, E. L., Detecção de objetos no futebol de robôs. 2017. Technical Report IC-PFG-17-08, Institute of Computing, University of Campinas.

${ }^{5}$ Michele Mancini. J-MOD2: Joint Monocular Obstacle Detection and Depth Estimation, 2018. IEEE Robotics and Automation Letters. 